\title{
Rancangan Sistem Informasi untuk Solusi Permasalahan Rumah Ibadah
}

\author{
Michael Yusdistira \\ Telkom University; \\ Email: michaelsaragi@student.telkomuniversity.ac.id
}

\begin{abstract}
Perancangan sistem informasi ini bertujuan agar para jemaat dapat beribadah meskipun tidak dapat beribadah di rumah ibadah, jadi dapat memudahkan para jemaat agar tetap beribadah meskipun di rumah, sistem informasi ini juga mempermudah pihak gereja dalam memberikan informasi. Metode yang digunakan oleh penulis merupakan metode waterfall. Hasil akhirnya menghasilkan sistem informasi yang berisi tentang nama minggu, injil khotbah, berita kelahiran, dan laporan keuangan mingguan. Penulis melakukan analisis dan perancangan sistem informasi menggunakan pemodelan Unified Modelling Language (UML) dan juga menggunakan Ms. Acces untuk membantu. Diharapkan kedepannya sistem informasi dapat dikembangkan dengan membuat laporan keuangan menjadi lebih rinci.
\end{abstract}

Keywords: system informasi, waterfall, warta jemaat, pendeta, tempat ibadah

Paper ini akan dipublikasikan di osf.io [1] menggunakan format standard perancangan sistem informasi [2]

\section{Introduction}

1.1. Business case

Dengan adanya pandemi ini banyak yang mengalami kerugian, seperti contohnya kita tidak bisa melakukan ibadah di tempat ibadah karena kita harus jaga jarak. Maka dari itu dianjurkan untuk beribadah di rumah agar dapat menghindari pandemi, demi membantu kegiatan tersebut maka saya akan memberikan usul sebuah sistem informasi yang dapat membantu rumah ibadah agar para jemaat dapat beribadah di rumah dengan mudah. Karena usul yang diberikan cukup sederhana maka dapat diseleseaikan dengan cepat namun sangat membantu para jemaat maupun pengurus rumah ibadah dalam melakukan ibadah di rumah.

\subsection{System Requirement}

Fitur yang ditawarkan dari sistem informasi ini adalah kita mampu melakukan kegiatan ibadah di rumah dengan persiapan yang bisa didapatkan dari admin berupa warta jemaat, sehingga jemaat dapat melakukan ibadah seperti biasa di rumah. Kita juga dapat mengetahui informasi keuangan yang dilakukan oleh gereja.

\section{Penjelasan SIngkat Terkait Metode}

Metode yang kami gunakan merupaka metode waterfall. Metode waterfall meruapakan salah satu siklus hidup klasik dalam pengembangan perangkat lunak. [1] Metode ini menggambarkan pendekatan yang cukup sistematis juga berurutan pada pengembangan software, dengan urutan sebagai berikut :

1. Requirements Analysis

2. Design

3. Development 
4. Testing

5. Maintenance

Maka dalam kasus ini penulis menggunakan metode waterfall seperti berikut.

1. Requirements analysis Informasi didapatkan dari hasil penglihatan saja untuk mengetahui apa yang dibutuhkan dan menjadi batasan software.

2. Design

Penulis membuat DFD, ERD, use case diagram, activity diagram, dan sequence diagram terlebih dahulu untuk mengetahui gambaran lengkap.

3. Implementation

Proses ini kami menggunakan Ms. Acces untuk membantu pengerjaan.

4. Testing

Pengujian bertujuan untuk mengetahui apakah software sudah sesuai dengan yang diinginkan dan untuk menunjukkan jika terjadi kesalahan.

5. Maintenance

Pemeliharaan berarti akan terjadi perbaikan masalah, perbaikan implementasi, dan peningkatan.

\section{Proses Perhitungan}

\subsection{System Design}

Dalam sistem desain terdapat 1 tabel yang berisi id warta jemaat, nama minggu, injil khotbah, berita kelahiran, dan laporan keuangan. Informasi tersebut didapatkan dari pihak yang bertanggung jawab pada di setiap bidangnya, kemudian admin akan memasukkan informasi tersebut sesuai dengan yang diberitahukan.

\subsection{Data Flow Diagram (DFD)}

Data Flow Diagram (DFD) merupakan suatu model yang dapat memberikan suatu tampilan secara visual, yang mana pada model tersebut dapat menggambarkan suatu aliran data maupun informasi pada sebuah system. [2]

a. DFD level 0, digambarkan sebagai berikut:

b. Data Flow Diagram (DFD)

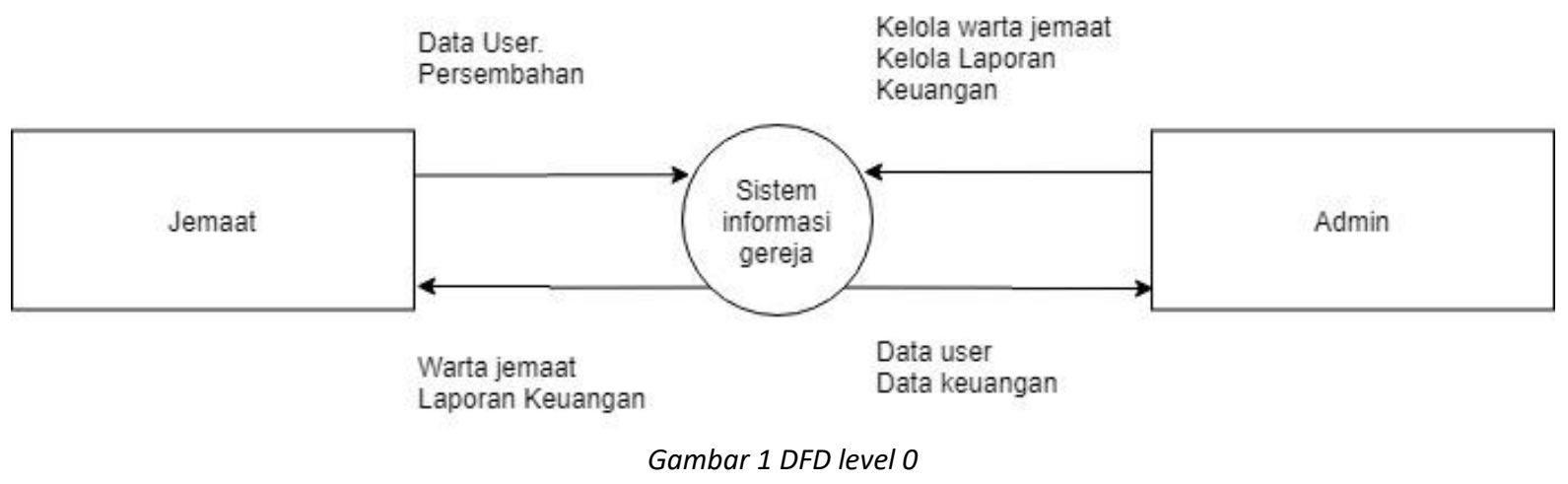


c. DFD level 1, digambarkan sebagai berikut:

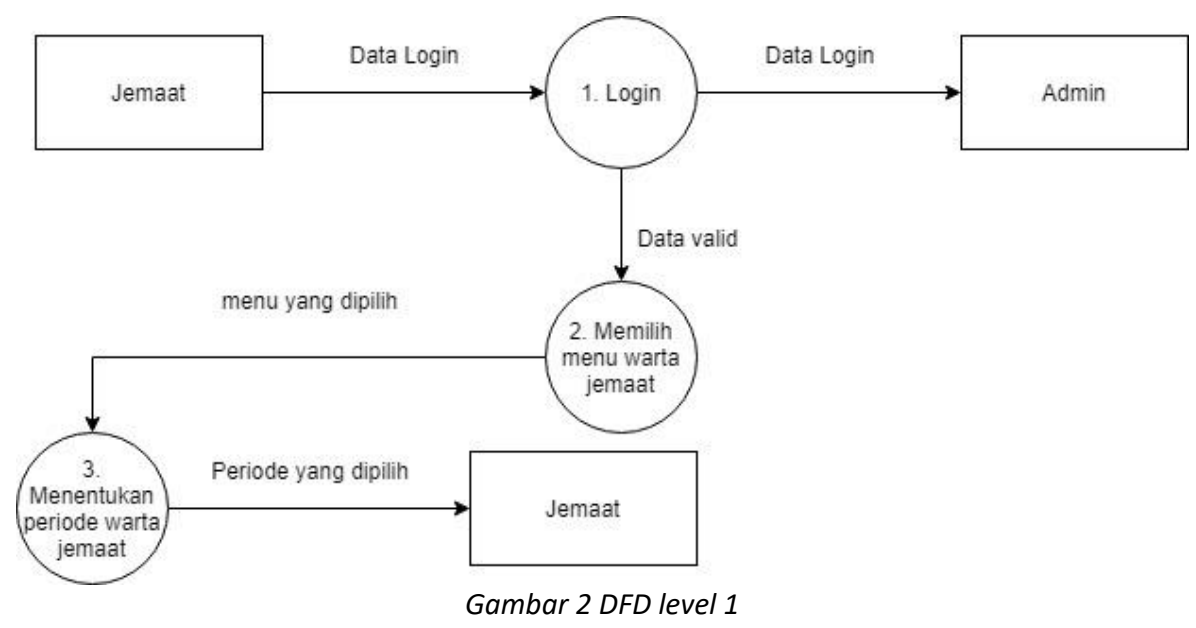

d. DFD level 2, digambarkan sebagai berikut:

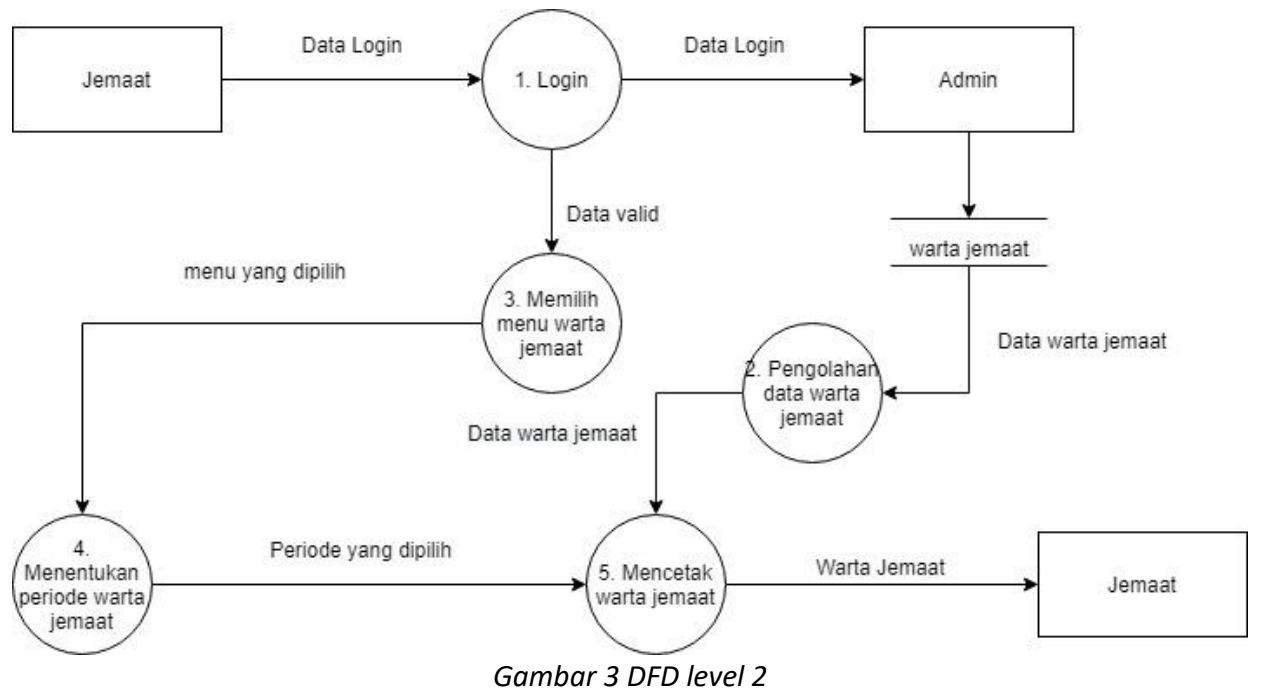

\subsection{Entity Relationship Diagram (ERD)}

Entity Relationship Diagram (ERD) adalah suatu model untuk menjelaskan hubungan antar data dalam basis data berdasarkan objek-objek dasar data yang memiliki hubungan antar relasi. [3]

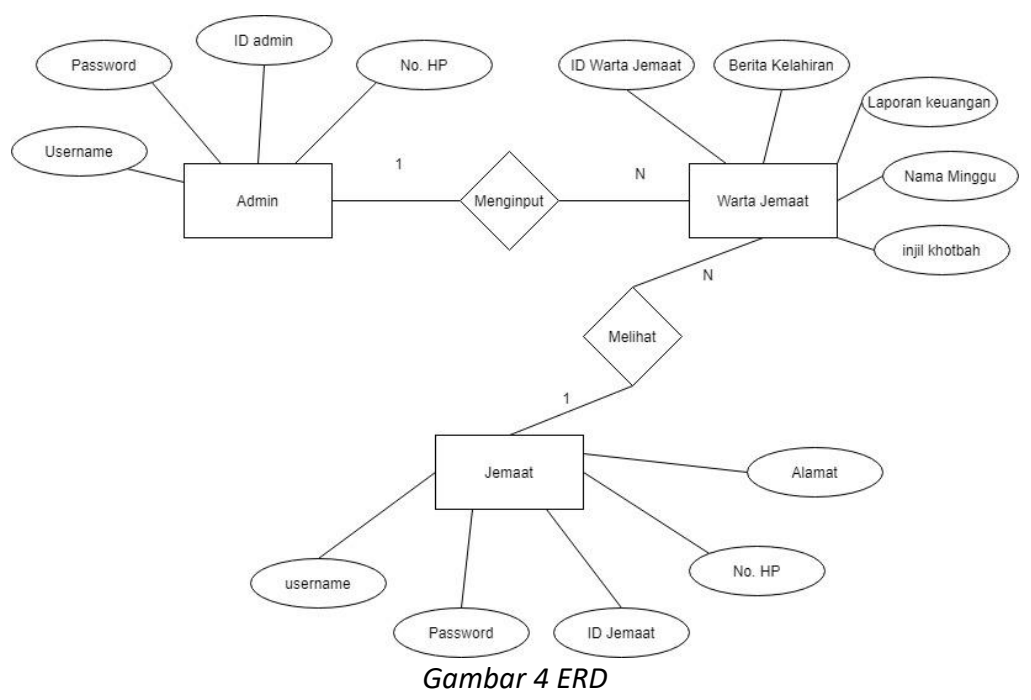




\subsection{Database Design}

Database design yang penulis ciptakan meliputi id warta jemaat, nama minggu, injil khutbah, berita kelahiran, dan laporan keuangan seperti sebagai berikut :

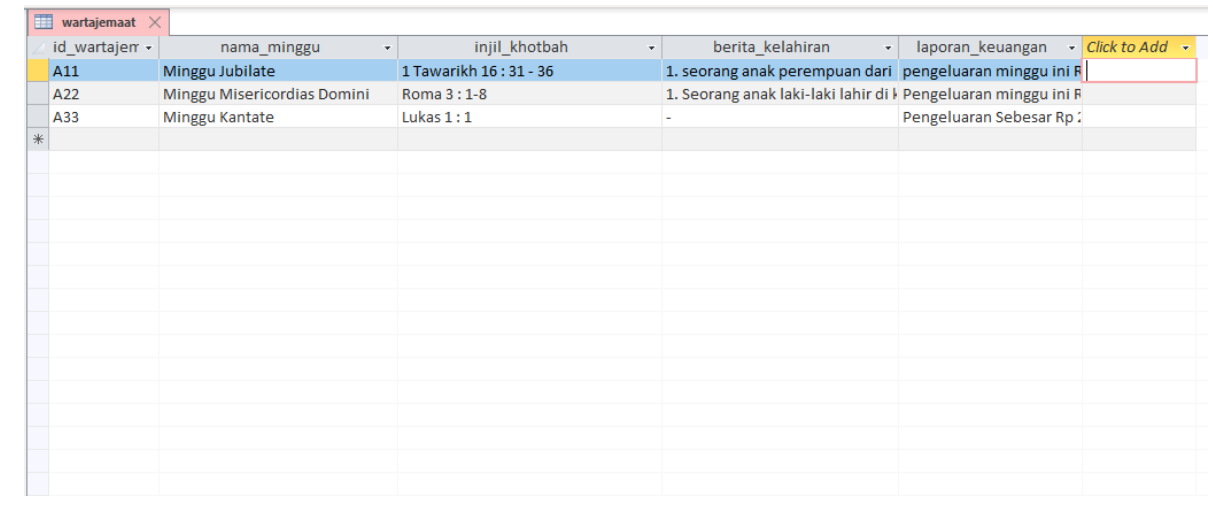

Gambar 5 database design

\subsection{Use Case Diagram}

Use Case Diagram adalah gambaran grafis dari beberapa atau semua actor, use case, dan interaksi diantaranya yang memperkenalkan suatu system. [4]

Berikut merupakan use case diagram dalam mencetak warta jemaat:

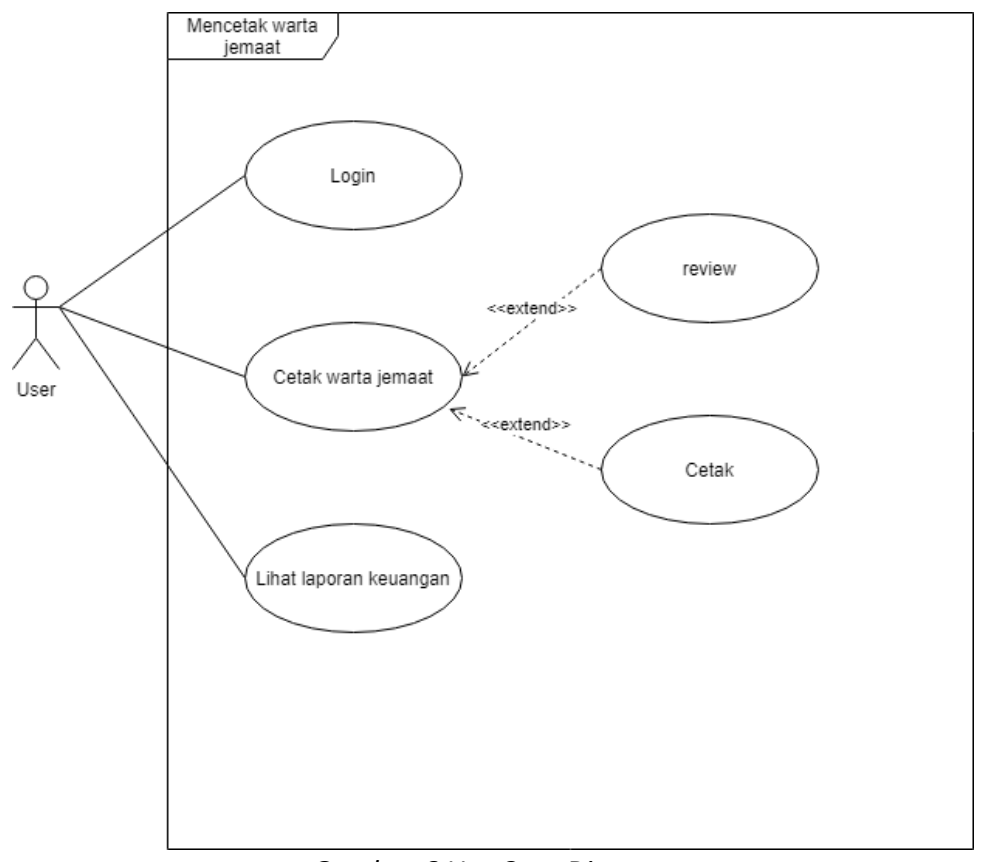

Gambar 6 Use Case Diagram 


\subsection{Activity Diagram}

Activity Diagram menggambarkan tentang aktifitas yang terjadi pada system. [5] Berikut merupakan activity diagram dalam mencetak warta jemaat:

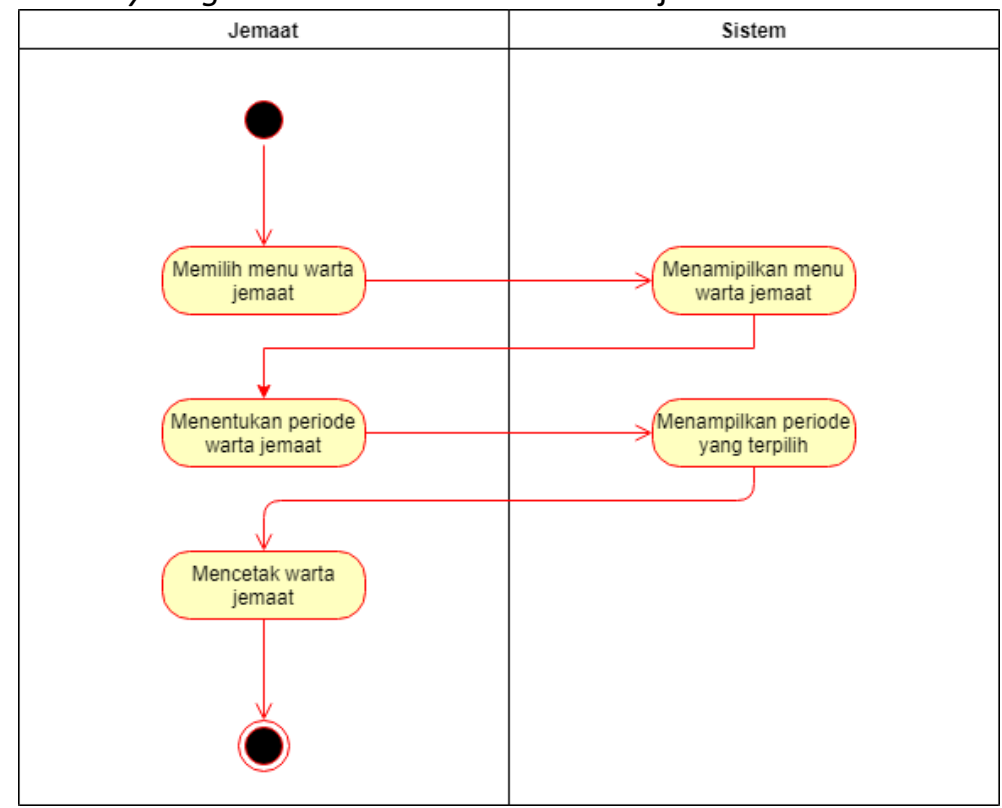

Gambar 7 Activity Diagram

\subsection{Sequence Diagram}

Sequence Diagram adalah salah satu dari diagram-diagram yang ada pada UML, sequence diagram ini adalah diagramyang menggambarkan kolaborasi dinamis antara sejumlah objek. [6] Berikut merupakan sequence diagram dalam mencetak warta jemaat:

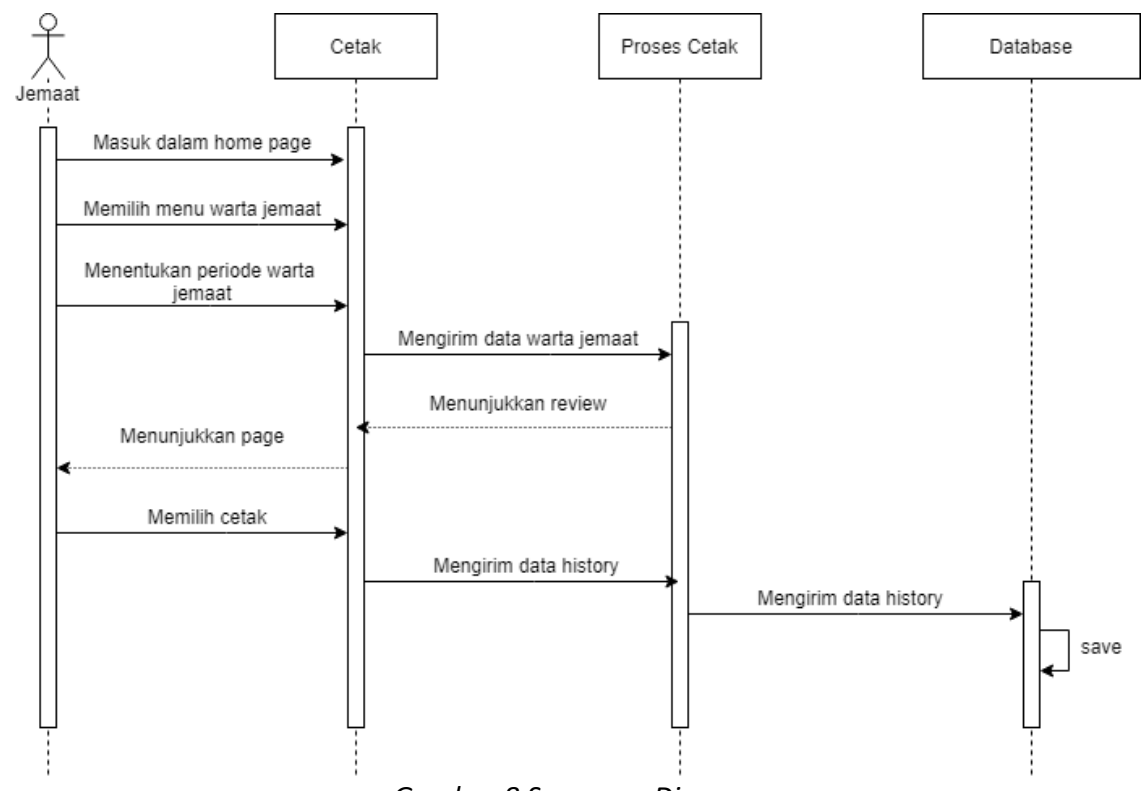

Gambar 8 Sequence Diagram 


\subsection{Interface Design}

Berikut merupakan Form dan Report dari rancangan sistem informasi.

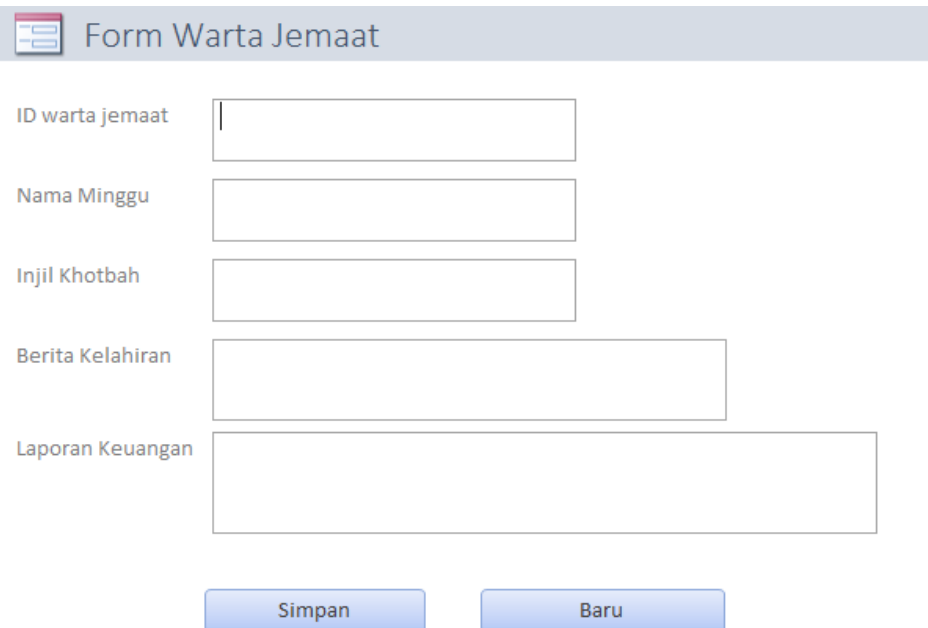

Gambar 9 Form

\begin{tabular}{|l|}
\hline Minggu Misericordias \\
Domini
\end{tabular}

Roma $3: 1-8$

Lukas 1: 1
1. Seorang anak laki-laki lahir di keluarga Steven, pada 4 Mei 2020 -
4.783.100

Pengeluaran minggu ini $\mathrm{Rp}$ 2.726.500

Pengeluaran Sebesar $\mathrm{Rp}$ 2.213.344 


\subsection{Source Code}

Berikut merupakan tampilan back end dari Ms. Acces, terdapat id warta jemaat, nama minggu, injil khotbah, berita kelahiran, dan laporan keuangan.

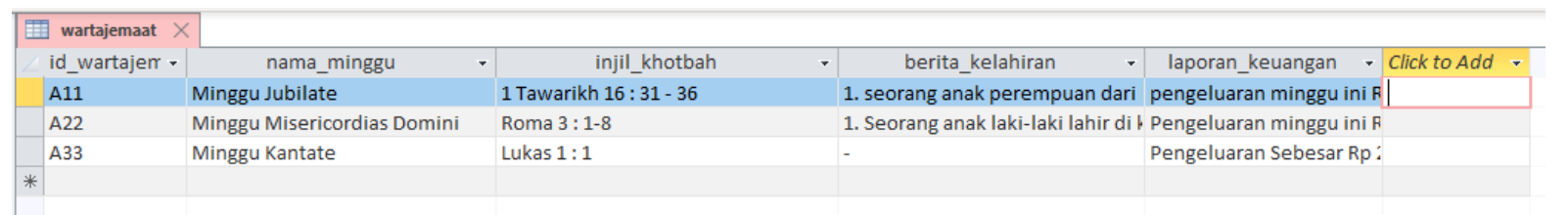

Gambar 11 Tampilan Back End

\section{Penutup}

\subsection{Kesimpulan}

Dalam sistem informasi ini terdapat warta jemaat yang berisi informasi tentang nama minggu, injil khotbah, berita kelahiran, dan laporan keuangan yang dikelola oleh admin berdasarkan informasi yang diberikan pendeta maupun jemaat itu sendiri.

Maka sistem informasi yang dibangun oleh penulis diharapkan akan memudahkan jemaat untuk tetap beribadah di rumah saat terjadinya pandemi seperti sekarang ini, sistem informasi ini juga memudahkan pihak gereja untuk tetap memberikan informasi penting kepada jemaatnya.

\subsection{Saran}

Sistem informasi yang diciptakan oleh penulis memiliki banyak kekurangan dan masih dapat dikembangkan sehingga menjadi lebih lengkap, seperti saran berikut:

1. Pada bagian keuangan masih bisa dibuat menjadi lebih rinci.

2. Sistem informasi dapat dibuat menjadi aplikasi sehingga bisa digunakan melalui smartphone. 


\section{References}

[1] Guntoro, "Metode Waterfall : Pengertian, Tahapan, Contoh, Kelebihan dan Kekurangan," 11 March 2020. [Online]. Available: https://badoystudio.com/metode-waterfall/.

[2] S. F. Fadillah, "Pengertian DFD (Data Flow Diagram) Beserta Fungsi dan Simbol-Simbol DFD," 31 Agustus 2019. [Online]. Available: https://www.nesabamedia.com/pengertian-dfd/.

[3] Admin, "Pengertian Entity Relationship Diagram (ERD)," 17 Maret 2018. [Online]. Available: https://pendidikanku.org/2018/03/pengertian-entity-relationship-diagram-erd.html.

[4] A. R. Pratama, "Belajar UML - Use Case Diagram," 21 Januari 2019. [Online]. Available: https://www.codepolitan.com/mengenal-uml-diagram-use-case.

[5] A. R. Pratama, "Belajar UML - Activity Diagram," 21 Januari 2019. [Online]. Available: https://www.codepolitan.com/mengenal-uml-contoh-uml-diagram-model-activity-diagram.

[6] A. R. Pratama, "Belajar UML - Sequence Diagram," 21 Januari 2019. [Online]. Available: https://www.codepolitan.com/belajar-uml-sequence-diagram-57fdb1a5ba777-17044.

[a] R. Aurachman, "Review Terhadap OSF.IO Sebagai Sarana Publikasi Preprint," OSF Preprints, 17 May 2020. doi:10.31219 [2]/osf.io/rvumx [5] , Available: https://osf.io rvumx [4] [6]

[b] R. Aurachman, "Kerangka Perancangan Sistem Informasi Sebagai Pembelajaran Mahasiswa Teknik Industri," osf.io, doi:10.31219/osf.io/tmpen , 5 2020. Available: https://osf.io/tmpen 